\title{
ENDOSCOPIC EVALUATION OF POST-FUNDOPLICATION ANATOMY AND CORRELATION WITH SYMPTOMATOLOGY
}

\author{
Avaliação endoscópica da anatomia após fundoplicatura e correlação com sintomatologia
}

\author{
Bruno Costa MARTINS ${ }^{1 \oplus}$, Clarissa Santos SOUZA ${ }^{1 \oplus}$, Jennifer Nakamura RUAS $^{1 \oplus}{ }^{\oplus}$, Carlos Kiyoshi \\ FURUYA $^{1 \oplus}$, Sonia Nadia FYLYK ${ }^{1 \oplus}$, Christiano Makoto SAKAI ${ }^{1 \oplus}$, Edson IDE ${ }^{1 \oplus}$
}

ABSTRACT - Background: Upper digestive endoscopy is important for the evaluation of patients submitted to fundoplication, especially to elucidate postoperative symptoms. However, endoscopic assessment of fundoplication anatomy and its complications is poorly standardized among endoscopists, which leads to inadequate agreement. Aim: To assess the frequency of postoperative abnormalities of fundoplication anatomy using a modified endoscopic classification and to correlate endoscopic findings with clinical symptoms. Method: This is a prospective observational study, conducted at a single center. Patients were submitted to a questionnaire for data collection. Endoscopic assessment of fundoplication was performed according to the classification in study, which considered four anatomical parameters including the gastroesophageal junction position in frontal view (above or at the level of the pressure zone); valve position at retroflex view (intra-abdominal or migrated); valve conformation (total, partial, disrupted or twisted) and paraesophageal hernia (present or absent). Results: One hundred patients submitted to fundoplication were evaluated, 51\% male (mean age: 55.6 years). Forty-three percent reported postoperative symptoms. Endoscopic abnormalities of fundoplication anatomy were reported in $46 \%$ of patients. Gastroesophageal junction above the pressure zone (slipped fundoplication), and migrated fundoplication, were significantly correlated with the occurrence of postoperative symptoms. There was no correlation between symptoms and conformation of the fundoplication (total, partial or twisted). Conclusion: This modified endoscopic classification proposal of fundoplication anatomy is reproducible and seems to correlate with symptomatology. The most frequent abnormalities observed were slipped and migrated fundoplication, and both correlated with the presence of symptoms.

HEADINGS: Fundoplication. Endoscopy. Gastroesophageal reflux disease. Digestive system surgical procedures.

RESUMO - Racional: A endoscopia digestiva alta é importante ferramenta para a avaliação de pacientes submetidos à fundoplicatura, principalmente para elucidar os sintomas pósoperatórios. Entretanto, a avaliação endoscópica da sua anatomia e complicações é atualmente pouco padronizada entre os endoscopistas, o que leva à disparidade de laudos e condutas. Objetivo: Avaliar a frequência de anormalidades pós-operatórias da fundoplicatura através de uma classificação endoscópica e correlacionar os achados endoscópicos com os sintomas clínicos. Método: Este é estudo observacional prospectivo, realizado em um único centro. Os pacientes foram submetidos a um questionário para coleta de dados. A avaliação endoscópica da fundoplicatura foi realizada de acordo com a classificação em estudo, que considerou quatro parâmetros anatômicos, incluindo a posição da junção gastroesofágica em vista frontal (acima ou no nível da zona de pressão); posição da válvula na visão retroflexa (intra-abdominal ou migrada); conformação valvar (total, parcial, desgarrada ou torcida) e hérnia paraesofágica (presente ou ausente). Resultados: Foram avaliados 100 pacientes submetidos à fundoplicatura, $51 \%$ homens (idade média: 55,6 anos). Quarenta e três por cento relataram sintomas pósoperatórios. Anormalidades endoscópicas da anatomia da fundoplicatura foram relatadas em $46 \%$ dos pacientes. Junção gastroesofágica acima da zona de pressão (fundoplicatura deslizada) e fundoplicatura migrada foram significativamente correlacionadas com a ocorrência de sintomas pós-operatórios. Não houve correlação entre sintomas e conformação da fundoplicatura (total, parcial ou torcida). Conclusão: Essa classificação endoscópica modificada proposta para avaliar a anatomia da fundoplicatura é reprodutível e parece correlacionar-se com a sintomatologia. As anormalidades mais frequentes observadas foram fundoplicaturas migradas e deslizadas, $\mathrm{e}$ ambas se correlacionaram com a presença de sintomas.

DESCRITORES: Fundoplicatura. Endoscopia digestiva. Doença do refluxo gastroesofágico. Cirurgia do aparelho digestivo.

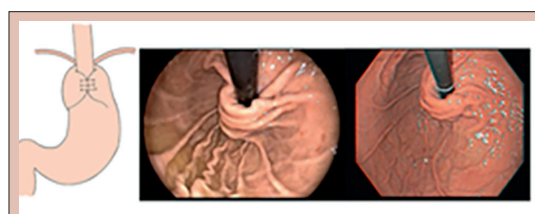

Endoscopic aspect of fundoplication anatomy: Normal aspect of Nissen fundoplication

Central message
This standardized endoscopic classification of
fundoplication anatomy is reproducible and easy to
apply. Slipped and migrated fundoplication were the
most common abnormalities, and both correlated
with symptoms.

\begin{tabular}{l}
\hline Perspective \\
Endoscopists face difficulties evaluating post- \\
fundoplication abnormalities, since it is poorly \\
standardized. This prospective study applied a \\
standardized classification for endoscopic evaluation \\
of fundoplication anatomy and demonstrated that \\
this classification is reproducible and has a good \\
correlation with symptomatology. The most frequent \\
abnormalities observed were slipped and migrated \\
fundoplication and both correlated with the presence \\
of symptoms.
\end{tabular}

\section{Perspective} applied a standardized classification for endoscopic evaluation fundoplication anatomy and demonstrated that this classification is reproducible and has a good correlation with symptomatology. The most frequent fundoplication and both correlated with the presence of symptoms.
Financial source: none

Conflict of interest: none

Received for publication: 06/04/2020

Accepted for publication: 12/07/2020 


\section{INTRODUCTION}

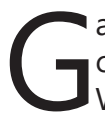
astroesophageal reflux disease (GERD) is the most common upper gastrointestinal benign disease in Western countries, with a prevalence of $10-20 \% 6,20,22,26$. The role of surgery in the treatment is well established. Laparoscopic fundoplication (LFP) is considered an effective alternative to drug treatment and is associated with excellent short and long-term outcomes (80-95\%) $3,4,5,7,17,23,24,28$. The goal of surgical treatment is to make a symmetrical fundoplication around the distal esophagus, situated below the closed hiatus (hiatoplasty) ${ }^{21}$.

Concurrent with the increase number of LFP over the last two decades ${ }^{8,14,16,21}$ the number of dissatisfied patients, presenting relapses or new symptoms after surgery has also arrised ${ }^{2,11,16,21}$. Given this scenario, precise endoscopic evaluation of valve fundoplication is extremely important because it allows the medical team to recognize abnormalities and to establish treatment strategies, especially if surgical reintervention is being considered ${ }^{21,25}$. However, there is currently no definitive standardization in the description of endoscopic findings and most of the analyzes are subjective, with poor agreement among endoscopists ${ }^{10,16,21}$. Therefore, endoscopic reports adds few information to guide surgeons about abnormalities present.

Mittal et $\mathrm{a}^{21}$ proposed a classification of endoscopic findings of fundoplications based on the evaluation of four anatomical parameters that could identify postoperative abnormalities: the gastroesophageal junction location and its relation to the crura, relationship of the fundoplication to the gastroesophageal junction (GEJ), a description of the fundoplication, and any sign of paraesophageal hernia. The authorsjudge that this classification was applicable to previous endoscopic reports, with good correlation with symptoms ${ }^{21}$.

Considering the need for greater uniformity of endoscopic description of fundoplications, we implemented an endoscopic classification in our service, based on the classification proposed by Mittal et $\mathrm{al}^{21}$, with some modifications in order to facilitate its applicability.

The objective of this study was to access the frequency of post-fundoplication abnormalities using a simplified and objective endoscopic criteria evaluation and to analyze if there is any correlation between endoscopic abnormalities and symptomatology.

\section{METHOD}

This study was approved by the ethical committee of our hospital and all included patients freely signed an informed consent form.

From September 2014 to July 2015, all patients scheduled to routine upper endoscopy who had been submitted to fundoplication surgery (open or laparoscopic) were included in this study. At our endoscopy division, we receive patients from all over the country, so fundoplication surgery could have been performed anywhere else. Before endoscopy, they were submitted to a questionnaire to collect data regarding gender, age, pre and postoperative symptoms, postoperative interval after fundoplication and whether or not a reoperation had occurred. After the interview, patients were submitted to conventional upper gastrointestinal endoscopy, with an objective evaluation of the fundoplication.

Upper endoscopies were performed by all doctors of our endoscopy team (five endoscopists), which were trained to apply the referred classification. After obtaining personal data and individualized classification of fundoplications, statistical analyzes were performed to evaluate the occurrence of LFP abnormalities and to correlate clinical and endoscopic findings.

Endoscopic evaluation of fundoplication (Figure 1) GEJ position in frontal view

\section{GEJ located at the pressure zone}

Pressure zone is composed by crura plus fundoplication valve (endoscopically separation of these two structures is usually not possible). This means that the GEJ is surrounded by the fundoplication valve (admitted as normal if extending $\leq 1 \mathrm{~cm}$ above the pressure zone), as shown in Figure $2 \mathrm{~A}$.

GEJ above the pressure zone

Located $1-2 \mathrm{~cm}$ above the pressure zone.

Slipped fundoplication

GEJ $>2 \mathrm{~cm}$ above the pressure zone, simulating a hiatal hernia. This situation represents a slipped fundoplication, which instead of involving the $Z$ line, involves the stomach itself (gastrogastric fundoplication), as seen in Figure $2 \mathrm{~F}$.

\section{Fundoplication position/situation (at retroflex view)}

Intra-abdominal fundoplication

Valve fundoplication located below hiatoplasty.

Partially migrated fundoplication

Valve fundoplication partially migrated towards the thorax, due to a loose or partially disrupted hiatoplasty.

\section{Fully migrated fundoplication}

Valve fundoplication fully migrated to the thorax, above the diaphragmatic, as depicted in Figure $2 \mathrm{E}$.

\section{Conformation of fundoplication (at retroflex view)}

\section{Total (or complete) fundoplication}

The transverse gastric folds circumferentially involve the cardia as observed in retroflexed position, remaining juxtaposed to the endoscope shaft in all phases of respiration. The fundoplication creates a nipple valve with stacked coil appearance about $3 \mathrm{~cm}$ long that should rest parallel to the white distance lines of the endoscope ${ }^{20}$. This conformation resembles the letter $U$ (Figure $2 \mathrm{~A})$. Very thick fundoplications may cause dysphagia while very thin ones may not be effective.

\section{Partial fundoplication}

The transverse gastric folds partially involve the cardia. Its conformation resembles the Greek letter "omega" and exposure of the Z-line may occur with breathing movements ${ }^{20}$. This finding may represent a partial disruption of the Nissen LFP valve (originally complete $-360^{\circ}$ ) or correspond to the Toupet-Lind LFP in which a valve that partially involves the cardia $\left(270^{\circ}\right)$ is intentionally made. Thus, this conformation does not always mean an "abnormality" (Figure 2B).

\section{Disrupted fundoplication}

The transverse gastric fold does not involve the endoscope shaft. Sometimes the gastric fold is not even perceptible. Occasionally it can be seen making a straight line at the cardia (Figure 2C).

Twisted fundoplication

The gastric fold is in an oblique position and is not parallel to the endoscope's demarcation lines. A craniocaudal axis deviation of the fundoplication valve is seen (Figure 2D).

\section{Paraesophageal hernia}

No paraesophageal hernia is the expected situation

Presence of paraesophageal hernia

Although valve fundoplication is intact, the hiatoplasty may be enlarged, allowing fundus tissue to slide towards the thorax (Figure 2G). 


\section{GEJ position}

GEJ located at the pressure zone

GEJ located above the pressure zone

Slipped fundoplication

Fundoplication position

Intra-abdominal fundoplication

Partially migrated fundoplication

Totally migrated fundoplication

Fundoplication morphology

Total fundoplication (completely wraps cardia)

Partial fundoplication (partially wraps cardia)

Disrupted fundoplication

Twisted fundoplication

Paraesophageal hernia

Present

Absent

GEJ=gastroesophageal junction

FIGURE 1 - Endoscopic evaluation of fundoplication anatomy
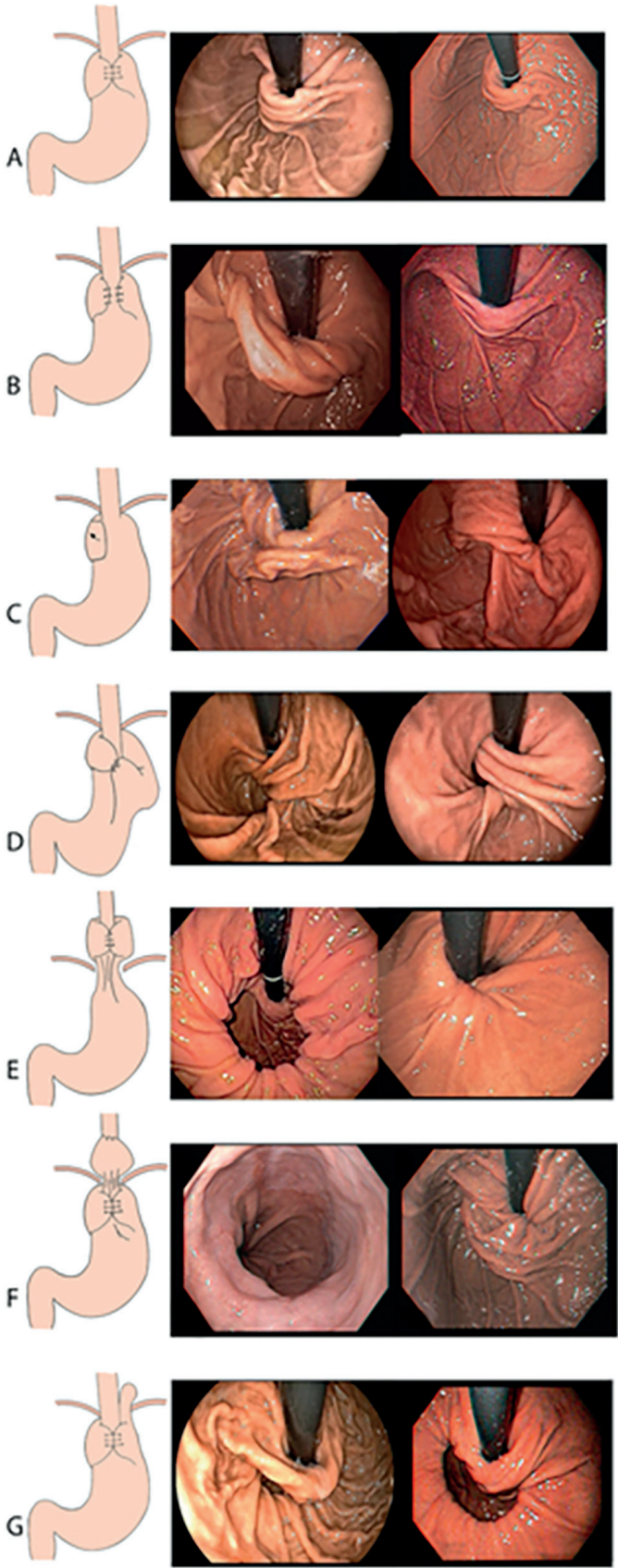

FIGURE 2 - Endoscopic aspect of fundoplication anatomy: A) normal aspect of Nissen fundoplication; B) partial fundoplication; C) disrupted fundoplication; D) twisted fundoplication; E) migrated fundoplication F) slipped fundoplication; G) paraesophageal hernia.
In summary, the "ideal" fundoplication (Figure 2A) should present: 1) GEJ near or at the pressure zone; 2) intra-abdominal position; 3) partially or totally involving the cardia; and 4) no paraesophageal hernia.

Original surgical reports were not available, as patients could have been operated outside our hospital. (For the sake of better understanding our results, the reader must be aware that the most common technique performed in Brazil is Nissen, followed by Toupet-Lind ${ }^{19}$. Anterior fundoplication is extremely rare in our country).

\section{Statistical analysis}

Categorical variables were presented in figures and in tables containing absolute $(\mathrm{n})$ and relative $(\%)$ frequencies. The association between these variables was assessed using the Chisquared test or Fisher's exact test. Calculations were performed by StatPlus: mac software (AnalystSoft Inc.).

RESULTS

Of the 100 evaluated patients, 51 were male; mean age was 55.6years (15-87y). Most patients (56) had fundoplication performed less than five years before endoscopy; 20 were operated 6 to 10 years before, and 24 had surgery more than 10 years earlier. Only eight patients were submitted to reoperation.

The most frequent preoperative symptoms were heartburn (73\%) and regurgitation (59\%). At the time of endoscopy, the majority (57\%) had no symptoms, as shown in Table 1.

TABLE1 - Prevalence of preoperative and postoperative symptoms.

\begin{tabular}{|c|c|c|}
\hline Symptoms $(\mathrm{n}=100)$ & $\begin{array}{c}\text { Preoperative } \\
\text { symptoms (\%) }\end{array}$ & $\begin{array}{c}\text { Postoperative } \\
\text { symptoms (\%) }\end{array}$ \\
\hline Heartburn & 73 & 23 \\
\hline Regurgitation & 59 & 8 \\
\hline Retrosternal pain & 32 & 5 \\
\hline Cough & 12 & 3 \\
\hline Abdominal pain & 4 & 6 \\
\hline Dysphagia & 3 & 12 \\
\hline Asymptomatic & 2 & 57 \\
\hline
\end{tabular}

\section{Characteristics of fundoplication}

With respect to endoscopic evaluation, fundoplication was adequate in more than $70 \%$ of the cases for the four parameters used: 1) position of the GEJ;2) fundoplication position; 3) fundoplication conformation; and 4) presence of paraesophageal hernia.

The most common abnormalities were: GEJ above pressure zone or slipped (28\%), fundoplication migration (25\%) and partial fundoplication (16\%). Only 4\% had paraesophageal hernia. These results can be seen in Table 2 .

TABLE 2 - Evaluation of the fundoplication parameters

\begin{tabular}{|c|c|}
\hline Evaluated parameters & Observed frequency \\
\hline \multicolumn{2}{|l|}{ GEJ position } \\
\hline At the pressure zone ${ }^{+}$ & $72 \%$ \\
\hline Above pressure zone or slipped & $28 \%$ \\
\hline \multicolumn{2}{|l|}{ Fundoplication position } \\
\hline Intra-abdominal $^{+}$ & $75 \%$ \\
\hline Partially migrated & $12 \%$ \\
\hline Totally migrated & $13 \%$ \\
\hline \multicolumn{2}{|l|}{ Fundoplication conformation } \\
\hline Total $^{+}$ & $75 \%$ \\
\hline Partial & $16 \%$ \\
\hline Disrupted & $7 \%$ \\
\hline Twisted & $2 \%$ \\
\hline \multicolumn{2}{|l|}{ Paraesophageal hernia } \\
\hline Absent $^{+}$ & $96 \%$ \\
\hline Present & $4 \%$ \\
\hline
\end{tabular}

=parameters indicating "ideal" fundoplication 

anatomy

Correlation between symptomatology and fundoplication

The number of asymptomatic patients when the GEJ was at the pressure zone was significantly higher than when the GEJ was above it or slipped ( $68 \%$ vs. $28.5 \%, \mathrm{p}<0.001)$, as shown in Figure 3. The same was observed when we assessed fundoplication position. The number of asymptomatic patients was higher when fundoplication was intra-abdominally, compared to partially or totally migrated fundoplications $(66.6 \%$ vs. $28.0 \%$, $p<0.001)$.

In contrast, there was no statistical significance between fundoplication conformations (total, partial, disrupted or twisted) and symptomatology. Of the patients with total LFP, $60.8 \%$ reported being asymptomatic vs. $46.1 \%$ with other descriptions $(p=0.19)$.

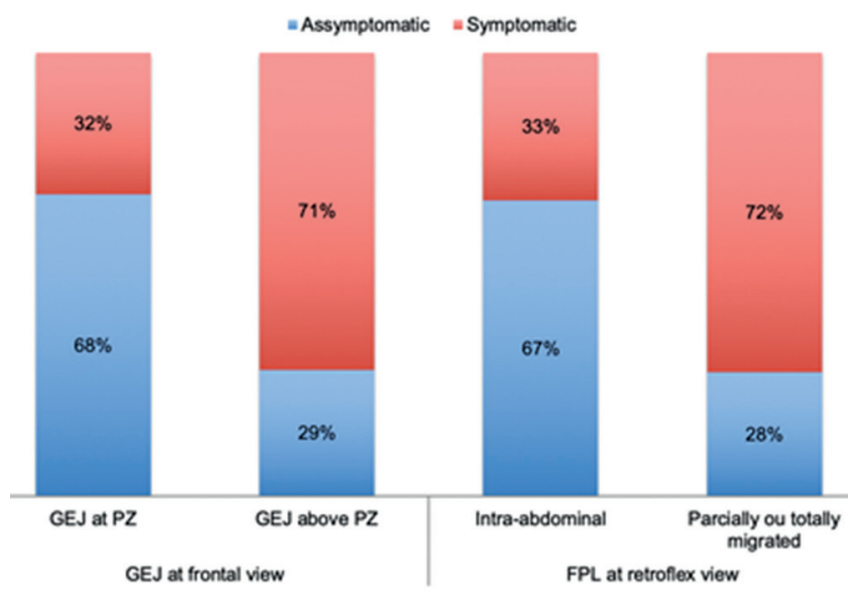

$\mathrm{PZ}=$ pressure zone; $\mathrm{GEJ}=$ gastroesophageal junction; $\mathrm{FPL}=$ fundoplication

FIGURE 3 - Correlation between the presence of symptoms and the endoscopic evaluation: position of the GEJ at frontal view and position of the fundoplication at retroflex view.

\section{DISCUSSION}

Studies analyzing long-term results of anti-reflux surgery, with follow-ups varying from 5-12 years, reveal that 2-30\% of patients may present recurrence, persistence or new symptoms related to gastroesophageal reflux disease ${ }^{12}$. In this scenario, a precise endoscopic evaluation is critical for diagnostic elucidation. In our study, $43 \%$ of patients reported one or more postoperative symptoms, and we found an association between symptomatology and fundoplication abnormalities.

Upper digestive endoscopy is generally indicated as the first diagnostic test to evaluate fundoplication ${ }^{15}$. However, endoscopists have difficulty evaluating FPL anatomy, specially FPL abnormalities, which may be overlooked or underestimated. This might be in part by fear of criticizing the surgeon, but also because of a lack of adequate standardization for evaluation. The concept that FPL abnormalities are better diagnosed by contrast studies than by endoscopy is incorrect. As a matter of fact, radiologists may even have more difficulty than endoscopists to fully understand the fundoplication anatomy. In fact, a study evaluating fundoplication integrity in 22 patients with postoperative symptoms showed that the abnormalities described by endoscopy were twice higher than the abnormalities described by esophagogram ${ }^{13}$.

Familiarity with fundoplication surgical steps seems to be important for its correct evaluation. Juhasz et al ${ }_{1}^{16}$ compared the endoscopic findings of fundoplication abnormalities reported by outside endoscopists (community gastroenterologists) vs. the authors' findings (esophageal center). Only $32 \%$ of outside physicians reported the presence of previous fundoplication. Furthermore, outside physicians diagnosed fewer slipped fundoplications (9/208 vs. $52 / 208, p<0.001)$ and fewer twisted fundoplications $(18 / 208$ vs. $61 / 208, \mathrm{p}<0.001)$, compared to experienced endoscopists.

Jobe et $\mathrm{al}^{15}$ uphold that the best method to evaluate a fundoplication is through endoscopy. They made the firstattemptto describe the endoscopic findings of normal successful fundoplications according to the different techniques and proposed an endoscopic lexicon to report these criteria. In their study, endoscopic images of fundoplications of asymptomatic patients were analyzed. From the evaluation of these images by experienced surgeons and gastroenterologists, ten criteria were elaborated to define an ideal fundoplication. They concluded that these criteria could be used during the evaluation of patients with complaints of the upper gastrointestinal tract after anti-reflux surgery and serve as a reliable evaluation method.

Mittal et $a^{21}$ evaluated symptomatic post-fundoplication patients who underwent reoperative antireflux surgeries and proposed a classification system to standardized endoscopic reports of fundoplication anatomy, demonstrating a good correlation to symptomatology. This study found out that chest pain and dysphagia were more associated to twisted fundoplication due to distal obstruction, while regurgitation and recurrent heartburn were frequently seen in disrupted fundoplication. In addition, the presence of slipped fundoplication tended to represent a complete failure of treatment and could be associated with any symptomatology evaluated. This system was proposed mainly to categorize patients who had failed fundoplication ${ }^{1,21}$

The classification proposed by Mittal et al ${ }^{21}$ was very helpful to understand post-fundoplication abnormalities; however, some aspects remained doubtful and could limit its applicability by a large number of endoscopists. The terms "partially disrupted fundoplication" should be avoided unless a previous endoscopy report have documented with images a well assembled total valve; "partial valve" (or "partial fundoplication)" is more adequate in this situation, since if we're examining a patient submitted to Lind-Toupet technique, this would be the normal aspect expected. Mittal et $\mathrm{al}^{21}$ argue that is important to differentiate the distance between GEJ and fundoplication from the distance between GEF and crura. Nevertheless, it is very difficult to make this distinction in practice. This difficulty can be overcome by analyzing a slipped fundoplication in the frontal view and a migrated valve at retroflex view. The subclassification F2b, described as two-compartment stomach, has no further explanation or illustrations to explain it, what could generate misunderstanding. This subclassification was suppressed in our system. Moreover, we gave preference to nominate the anatomical abnormalities instead of codifying it with letters and numbers, since we considered it easier to memorize this way.

In our study, we also observed that endoscopic evaluation of fundoplications helps to correlate the presence of symptoms and anatomical findings. Of the 100 fundoplication patients evaluated, $46 \%$ had some endoscopic surgery abnormality. When correlating the presence of symptoms with fundoplication evaluation, we observed that the GEJ outside the pressure zone and migrated fundoplication were significantly associated with the occurrence of symptoms ( $p<0.001$ in both cases).

Koch et $a{ }^{18}$ showed that Nissen and Toupet fundoplication procedures resulted in an expressive increase in lower esophageal sphincter pressure, but the improvement was significantly greater with the Nissen procedure ${ }^{18}$. However, postoperative results were similar in both surgeries, indicating that not only the lower esophageal sphincter pressure is important but also the adequate restoration of the gastroesophageal valve ${ }^{9}$. In our study, there was no correlation between the presence of symptoms and the conformation of the fundoplication (whether total, partial or twisted, $\mathrm{p}=0.19$ ).

This study has important limitations, especially the small number of patients included in the analysis and the fact that it was carried out in a single center. Unfortunately, we didn't had access to original surgical reports nor previous control endoscopies. However, this may have had minimal impact in our results as our main goal was to describe the current endoscopic anatomy and knowing the original surgical technique could have biased our description. Moreover, partial or total fundoplication had no 
correlation with symptoms. On the other hand, previous endoscopies reports could have helped in the diagnostic of valve disruption or migration. Additional information, such as correlation to manometry and $\mathrm{pH}$ study of the symptomatic group would bring important information in order to discriminate the symptoms directly related to GERD from functional gastrointestinal disorders not related to anti-reflux surgery. Another aspect not analyzed in this study was the fundoplication thickness. Ideal Nissen fundoplication should have a nipple valve about $2-3 \mathrm{~cm}$ long. Thinner fundoplication could be related to persistence or early relapse of reflux symptoms, and thicker fundoplication may relate to dysphagia.

\section{CONCLUSION}

This standardized endoscopic classification of fundoplication anatomy is reproducibleand seems to correlate with symptomatology. The most frequent abnormalities observed were slipped and migrated fundoplication, and both correlated with the presence of postoperative symptoms. There was no correlation between symptoms and endoscopic findings of total or partial fundoplication.

\section{REFERENCES}

1. Abdelmoaty, WF, Lee LS. Endoscopic evaluation of post-fundoplication anatomy. Current gastroenterology reports . 2017;19: 51.

2. Braghetto Italo, Csendes Attila. FAILURE AFTER FUNDOPLICATION: REFUNDOPLICATION? ISTHEREAROOM FOR GASTRECTOMY? INWHICH CLINICAL SCENARIES?. ABCD, arq. bras. cir. dig. 2019;32(2): e1440.

3. Broeders JAJL, Mauritz FA, Ali UA, Draaisma WA, Ruurda JP, Gooszen $\mathrm{HG}$, et al. Systematic review and meta-analysis of laparoscopic Nissen (posterior total) versus Toupet (posterior partial) fundoplication for gastro-oesophageal reflux disease. Br J Surg. 2010;97(9):1318-30.

4. Cowgill SM, Gillman R, Kraemer E, Al-Saadi S, Villadolid D, Rosemurgy A. Ten-year follow up after laparoscopic Nissen fundoplication for gastroesophageal reflux disease. Am Surg. 2007;73(8):748-52.

5. Dallemagne B, Weerts J, Markiewicz S, Dewandre JM, Wahlen C, Monami $B$, et al. Clinical results of laparoscopic fundoplication at ten years after surgery. Surg Endosc Other Interv Tech. 2006;20(1):159-65.

6. DentJ, El-Serag HB, Wallander MA, Johansson S. Epidemiology of gastrooesophageal reflux disease: A systematic review. Gut. 2005;54(5):710-7

7. Draaisma WA, Rijnhart-De Jong HG, Broeders IAMJ, Smout AJPM, Furnee EJB, Gooszen HG. Five-year subjective and objective results of laparoscopic and conventional Nissen fundoplication: A randomized trial. Ann Surg. 2006;244(1):34-41.

8. Finks JF, Wei Y, Birkmeyer JD. The rise and fall of antireflux surgery in the United States. Surg Endosc Other Interv Tech. 2006;20(11):1698-701.

9. FurnéeEJB,DraaismaWA,BroedersIAMJ,GooszenHG.Surgical reintervention after failed antireflux surgery: A systematic review of the literature. J Gastrointest Surg. 2009;13(8):1539-49.

10. Hatton PD, Selinkoff PM, Harford FJ. Surgical management of the failed Nissen fundoplication. Am J Surg. 1984;148(6):760-3.
11. Humphries LA, Hernandez JM, Clark W, Luberice K, Ross SB, Rosemurgy AS.Causes ofdissatisfactionafterlaparoscopicfundoplication:Theimpact of new symptoms, recurrent symptoms, and the patient experience. Surg Endosc. 2013;27(5):1537-45.

12. Hunter JG, Smith CD, Branum GD, Waring JP, Trus TL, Cornwell M, et al. Laparoscopic fundoplication failures: Patterns of failure and response to fundoplication revision. In: Annals of Surgery. 1999. p. 595-606.

13. Jailwala J, Massey B, Staff D, Shaker R, Hogan W. Post-fundoplication symptoms: Theroleforendoscopicassessmentoffundoplicationintegrity. Gastrointest Endosc. 2001 Sep;54(3):351-6.

14. Jay APM, Watson DI. Changing work patterns for benign upper gastrointestinal and biliary disease: 1994-2007: Upper gut surgery. ANZ J Surg. 2010;80(7-8):519-25.

15. Jobe BA, Kahrilas PJ, Vernon AH, Sandone C, Gopal DV., Swanstrom LL, et al. Endoscopic Appraisal of the Gastroesophageal Valve after Antireflux Surgery. Am J Gastroenterol. 2004;99(2):233-43.

16. Juhasz A, Sundaram A, Hoshino M, Lee TH, FilipiCJ, Mittal SK. Endoscopic assessment of failed fundoplication: A case for standardization. Surg Endosc. 2011;25(12):3761-6.

17. KellyJJ,WatsonDI,ChinKF,DevittPG, GamePA, JamiesonGG.Laparoscopic Nissen Fundoplication: Clinical Outcomes at 10 Years. J Am Coll Surg. 2007 Oct;205(4):570-5.

18. KochOO, KaindlstorferA,AntoniouSA, LuketinaRR, EmmanuelK, Pointner R. Comparison of results from a randomized trial 1 year afterlaparoscopic Nissen and Toupet fundoplications. Surg Endosc. 2013;27(7):2383-90.

19. Lima CÉMC, Silva Neto VR, Sales ZN. Técnicas cirúrgicas utilizadas para o tratamento da doença do refluxo gastroesofágico. Revista da Faculdade de Ciências Médicas de Sorocaba. 2015;7(4):188-192.

20. Marano S, Mattacchione S, Luongo B, Mingarelli V, Campagna G, Tosato F. Two-Year Subjective, Objective, Quality of Life, and Endoscopic Followup After Laparoscopic Nissen-Rossetti in Patients With Columnar-lined Esophagus. Surg Laparosc Endosc Percutan Tech. 2013 Jun;23(3):292-8.

21. Mittal SK, Juhasz A, Ramanan B, Hoshino M, Lee TH, Filipi CJ. A proposed classificationforuniformendoscopicdescription of surgical fundoplication. Surg Endosc. 2014 Apr;28(4):1103-9.

22. MoraisDJ,LopesLR,AndreolloNA.Dysphagiaafterantirefluxfundoplication: endoscopic, radiological and manometric evaluation. Arq Bras Cir Dig. 2015;27(4):251-5.

23. Ruiz-Tovar J, Diez-Tabernilla M, Chames A, Morales V, Martinez-Molina E. Clinical Outcome at 10 Years After Laparoscopic Versus Open Nissen Fundoplication. J Laparoendosc Adv Surg Tech. 2009;20(1):21-3.

24. Salminen PTP, Hiekkanen HI, RantalaAPT, OvaskaJT.Comparisonoflongterm outcome of laparoscopic and conventional Nissen fundoplication: A prospective randomized study with an 11-year follow-up. Ann Surg. 2007;246(2):201-6.

25. Spechler SJ. The Management of Patients Who Have "Failed" Antireflux Surgery, American Journal of Gastroenterology. 2004;99:552-61.

26. Staehelin A, Zingg U, Devitt PG, Esterman AJ, Smith L, Jamieson GG, et al. Preoperative factors predicting clinical outcome following laparoscopic fundoplication. World J Surg. 2014;38(6):1431-43.

27. Stark ME, Devault KR. Complications Following Fundoplication. Tech Gastrointest Endosc. 2006 Apr;8(2):40-53.

28. Strate U, Emmermann A, Fibbe C, Layer P, Zornig C. Laparoscopic fundoplication: Nissenversus Toupet two-year outcome of a prospective randomized study of 200 patients regarding preoperative esophageal motility. Surg Endosc Other Interv Tech. 2008;22(1):21-30. 